\title{
Pengaruh small sided games terhadap peningkatan vo2max
}

\section{The effect of small sided games to improvement VO2max}

\author{
Andy Supriady ${ }^{1}$ \\ ${ }^{1}$ Program studi PJKR, STKIP Pasundan, Cimahi, Jawa Barat, 40512, Indonesia
}

\begin{abstract}
Abstrak
Tujuan dari penelitian ini adalah untuk mengetahui pengaruh Small Sided Games terhadap peningkatan VO2Max. Metode penelitian menggunakan metode eksperimen dengan desain one group pretest-posttest design. Populasi dalam penelitian adalah pemain sepak bola PS Rick's Sayati dengan sample sebanyak 25 orang mengunakan teknik total sampling. Instrumen penelitian menggunakan Bleep Test. Hasil dari penelitian yang telah dianalisis dengan menggunakan teknik analisis paired sample T-test, dengan taraf signifikansi 0,05 (5\%). Dari uji tersebut diperoleh nilai sig 0,000<0,05. Apabila dilihat dari data mean difference sebesar 1,85. Maka Peningkatan persentase tersebut sebesar $5,39 \%$. Berdasarkan hasil penelitian ini dapat ditarik kesimpulan bahwa terdapat pengaruh yang signifikan metode Small Side Games terhadap peningkatan VO2max pada pemain sepak bola di PS Rick's Sayati.
\end{abstract}

Kata kunci: small sided games, VO2max.

\begin{abstract}
The purpose of this study was to find out the effect of Small Sided Games to improvement VO2Max. The research method uses the experimental method with one group pretestposttest design. The population in this study was PS Rick's Sayati soccer player with a sample of 25 people using a total sampling technique. Research instruments using the Bleep Test. The results of studies that have been analyzed using the paired sample T-test, with a significance level of 0.05 (5\%). From these tests a sig value of 0,000<0.05 was obtained. When viewed from the data average difference is 1.85. Then the percentage increase of 5.39\%. Based on the results of this study it can be concluded that there is a significant effect of the Small Sided Games method to Improvement VO2max soccer players on PS Rick's Sayati.
\end{abstract}

Keywords: small sided games, VO2max.

\section{PENDAHULUAN}

Kebugaran jasmani merupakan suatu kemampuan tubuh seseorang dalam melakukan pekerjaan sehari-hari secara efektif dan efisien dalam jangka waktu relatif lama tanpa menimbulkan kelelahan yang berlebihan, hal ini dimaksudkan untuk meningkatkan produktivitas yang dimiliki seseorang agar dapat terwujud derajat kesehatan dan kebugaran jasmani yang sesuai harapan (Depkes, 2015). Kebugaran jasmani memiliki 4 komponen dasar yaitu daya tahan jantung dan paru (kardiopulmonal), kekuatan dan daya tahan otot, kelenturan serta komposisi tubuh. Kebugaran daya tahan jantung dan paru di definisikan sebagai kapasitas maksimal untuk menghirup oksigen atau disingkat VO2max. Semakin tinggi VO2max maka ketahanan tubuh saat berolahraga 
juga semakin tinggi yang berarti seseorang yang memiliki tingkat VO2max tinggi tidak akan cepat lelah setelah melakukan berbagai aktivis(Bryantara, 2016).

Tingkat VO2max yang kurang dari 50\% tubuh akan bekerja secara aerob, maka lemak merupakan sumber energi utama, artinya seseorang yang memiliki VO2max kurang dari 50\% tidak cukup cepat untuk melakukan aktivitas latihan yang lebih intensif karena sumber energi yang berasal dari pembakaran lemak tersebut. Tubuh olahragawan atau atlet harus memiliki cadangan energi yang cukup agar dapat dimobilisasikan untuk menghasilkan energi. Cadangan energi yang berupa glikogen akan di simpan dalam otot dan hati, apabila cadang glikogen dalam tubuh atlet sedikit maka atlet tersebut akan mudah lelah karena kehabisan tenaga(Penelitian, 2012). Faktor yang berpengaruh terhadap kebugaran jasmani individu antara lain usia, jenis kelamin, genetik, status Indeks Massa Tubuh (IMT), dan aktivitas fisik, akan tetapi untuk tingkat kebugaran jasmani seorang olahragawan yang paling berpengaruh adalah usia dan status Indeks Massa Tubuh (IMT)(Depkes, 2015). Seorang atlet sepakbola wajib dan harus mampu menunjukkan kekuatan, kecepatan dan daya tahan selama 90 menit permainan(Almy, Akmal \& Sukadiyanto, 2014).

Ketika seseorang mempunyai nilai VO2max yang tinggi, orang tersebut akan lebih baik kondisinya dikarenakan dapat melakukan aktivitas lebih kuat di banding orang yang mempunyai nilai VO2max rendah. Tingkat kebugaran dapat diukur dari volume oksigennya, kelelahan atlet yang dirasakan akan menyebabkan turunnya konsentrasi sehingga tanpa konsentrasi yang prima terhadap suatu permainan, akan menyebabkan suatu kegagalan. Cepat atau lambatnya kelelahan oleh seorang atlet dapat diperkirakan dari kapasitas aerobic atlet yang kurang baik(Zakiyuddin, 2017).

Kapasitas aerobik menunjukan kapasitas maksimal yang dipergunakan oleh tubuh. Dan seperti kita ketahui, oksigen merupakan bahan bakar tubuh kita. Oksigen dibutuhkan oleh otot dalam melakukan setiap aktifitas berat maupun ringan. Semakin banyak oksigen yang diasup oleh tubuh menunjukan semakin baik kinerja otot dalam bekerja sehingga zat sisa-sisa yang menyebabkan kelelahan jumlahnya akan semakin sedikit. Manusia dalam setiap detiknya membutuhkan $\mathrm{O} 2$ untuk kelangsungan hidupnya. Secara rata-rata manusia tidak dapat mempertahankan hidupnya tanpa udara selama kurang dari tiga menit. VO2max diukur dalam banyaknya oksigen liter per menit atau banyaknya oksigen dalam mililiter per berat badan pada kilogram per menit. Sebagai pertimbangan dalam mengukur VO2max adalah tes yang harus diciptakan sedemikian rupa sehingga tekanan pada pasokan oksigen ke otot jantung harus berlangsung maksimal(Of \& Time, 2018). 
VO2max sangat dibutuhkan oleh para pemain sepakbola. Sering muncul masalah dalam persepakbolaan indonesia ialah tingkat VO2max para pemain lebih rendah dibandingkan pemain sepak bola di negara lain. Pemain sepak bola membutuhkan daya tahan aerobic, kelenturan, dan kekuatan otot serta memerlukan daya tahan anaerobic (stamina), kecepatan, kelincahan, power, dan daya tahan otot(Asmutiar, 2016). Kemampuan fisik pemain sepak bola memegang peranan penting dalam melaksanakan program kegiatan latihan, untuk mencapai peak performance yang maksimal. Kondisi fisik dan daya tahan yang sangat stabil sangat dibutuhkan untuk atlet sepak bola(Janwar, 2016). Kemapuan fisik ditujukan untuk meningkatkan kesegaran jasmani dan kemampuan fungsional dari sistem tubuh sehingga memungkinkan pemain sepak bola untuk mencapai prestasi yang lebih baik dalam bertanding. Bagaimanapun juga kemampuan teknik seorang pemain harus ditunjang oleh kondisi fisik yang prima. Berdasarkan pendapat tersebut, dapat dikatakan bahwa seorang pemain sepakbola tidak dapat bermain sampai kepuncak prestasi, bila tidak ditunjang oleh komponen kondisi fisik dan tehnik yang baik(Ngaglik \& Sma, 2016).

Small sided games merupakan salah satu bentuk latihan dalam cabang olahraga sepak bola, bentuk latihan ini diberikan untuk tujuan agar peningkatan penguasaan bola dan skill pemain(Pramdhan, n.d.). Small side games akan membantu pemain untuk meningkatkan kemampuan kapasitas anaerobik tanpa mengurangi kemampuan pemain dalam penguasaan bola(Kapasitas \& Terhadap, 2016).

Small Sided Games identic untuk meningkatkan teknik bermain dan pola permainan, latihan Small Sided Game juga bisa berpengaruh pada peningkatan daya tahan pemain dalam bermain sepak bola.

Latihan Small Sided Games adalah salah satu bentuk latihan yang memodifikasi permainan sepak bola dengan adanya pembatasan, meliputi pembatasan jumlah pemain, ukuran lapang, dan lama permaiann. Permainan penguasaan bola (possession) dan lapangan yang lebih kecil (Small Sided Games) dengan lebih sedikit pemain sangat baik untuk menumbuhkan pengertian taktis sekaligus mengasah kemampuan teknis pemain(F. Clemente et al., 2012).

Dikarenakan dalam permainan tersebut para pemain dituntut untuk selalu bergerak dengan kondisi lapangan yang dibatasi, seperti ukuran lapangan yang diperkecil, dan menggunkan peraturan permainan khusus misalnya dengan peraturan hanya boleh sekali dua kali menyentuh bola pembatasan jumlah pemain misalnya 1 lawan 2, 2 lawan 3, 2 lawan 4, 3 lawan 5,4 lawan 4, 5 lawan 5, 6 lawan 6 dan seterusnya, diatas kotak 
pinalti saja hanya setengah dari lapangan dan berbagai macam luas lapangan(Studi \& Jasmani, n.d.).

Latihan small sided game ini memenuhi kebutuhan mempertajam keterampilan teknik, pengamatan dan pengertian taktis permainan, serta juga sekaligus meningkatkan daya tahan pemain. Latihan Small Sided Games sangatlah bermanfaat bagi pemain sepak bola, banyak penelitian dan observasi telah dilakukan untuk menunjukkan bahwa anakanak mendapat kesenangan dalam melakukannya. Tidak lepas dari kekurangan dan kelebihan, metode Small Sided Games juga mempunyai kelebihan dan kekurangan.

Untuk dapat menerapkan latihan Small-Sided Games diperlukan pemahaman yang benar mengenai dosis latihan yang akan diberikan. Untuk tiap kelompok usia, tentu saja dosis yang diberikan akan berbeda, hal itu mengacu pada kemampuan tubuh yang berbeda-beda sesuai dengan usianya. Penerapan latihan Small-Sided Games dalam proses latihan keterampilan sepakbola dipandang mampu memberikan peningkatan penguasaan pelatihan yang lebih efektif, karena dengan menggunakan kotak-kotak latihan yang berukuran kecil, dan dilakukan oleh beberapa orang pemain akan mudah diawasi oleh pelatih. Dengan latihan Small Sided Games diharapkan latihan dapat berkembang, dengan menyajikan situasi permainan yang membuat pemain mendapatkan penguasaan aspek teknik, taktik, dan fisik sekaligus. Pemain dituntut untuk menghadapi situasi tekanan seolah-olah dalam situasi permainan yang sesungguhnya. Pemain berperan penting dalam mengambil keputusan yang tepat sesuai dengan permasalahan yang terjadi dalam permainan.

Hasil observasi dilapangan para pemain sepak bola PS Rick'Sayati mengalami kejenuhan dalam latihan, sehingga terjadi penurunan kondisi fisik. Maka dari itu setelah mengetahui bahwa pemain sepak bola merasa jenuh dengan program latihan seperti itu, saya sangat tertarik untuk memberikan suatu program Small Sided Games yang bertujuan untuk meningkatkan nilai VO2max para pemain, agar para pemain tidak merasa jenuh dengan program yang baru(Pramdhan, n.d.).

\section{METODE}

Metode penelitian menggunakan metode ekperimen. Dengan desain penelitian The One Group PretestPosttests Design(Fraenkel, Jack R., Wallen, 2009).

$$
\text { O1 } \quad \mathrm{X} \quad \mathrm{O2}
$$

\section{Gambar 1. The One Group PretestPosttest Design}

Keterangan: 
$\mathrm{X}:$ Treatment/Perlakuan yang diberikan

O1: Tes awal (pretest) kelompok eksperimen

O2: Tes akhir (posttest) kelompok eksperimen

Populasi adalah pemain sepak bola PS Rick's Sayati sebanyak 25 orang. Prosedur pengambilan sample menggunakan Teknik Total Sampling. Instrumen penelitian menggunkan Test VO2max Beep Test(Ernesto et al., 2015).

Teknik analisis data yang digunakan adalah analisis uji Paried Sample T-test untuk mengolah data.

\section{HASIL DAN PEMBAHASAN}

\section{Hasil}

Hasil pengolahan data bisa dilihat pada tabel berikut.

Tabel 1. Rata- rata dan Simpangan baku

\begin{tabular}{lllll}
\hline Tes & Perlakuan & N & Rata - rata & Simpangan Baku \\
\hline Pre test & Small Sided Games & 25 & 34,28 & 2,19 \\
Post test & Small Sided Games & 25 & 36,13 & 2,16 \\
\hline
\end{tabular}

Deskripsi hasil data Pretest VO2max

Pada hasil test awal mendapatkan niali rata-rata sebesar 34,28 dan simpangan baku sebesar 2,19. Deskripsi hasil Pretest disajikan dalam bentuk tabel frekuensi, yaitu :

Tabel 2.Kriteria penilaian Pretest

\begin{tabular}{llll}
\hline Kriteria & Nilai & Frekuensi & Persentase \\
\hline Sangat kurang & $<35,0$ & 14 & $56 \%$ \\
Kurang & $35,0-38,3$ & 11 & $44 \%$ \\
Cukup & $38,4-45,1$ & 0 & $0 \%$ \\
Baik & $45,2-50,9$ & 0 & $0 \%$ \\
Sangat baik & $51,0-55,9$ & 0 & $0 \%$ \\
Luar Biasa & $>55,9$ & 0 & $0 \%$ \\
\hline Jumlah & & 25 & $100 \%$
\end{tabular}

Apabila ditampilkan pada diagram batang bisa dilihat pada tabel diawah ini:

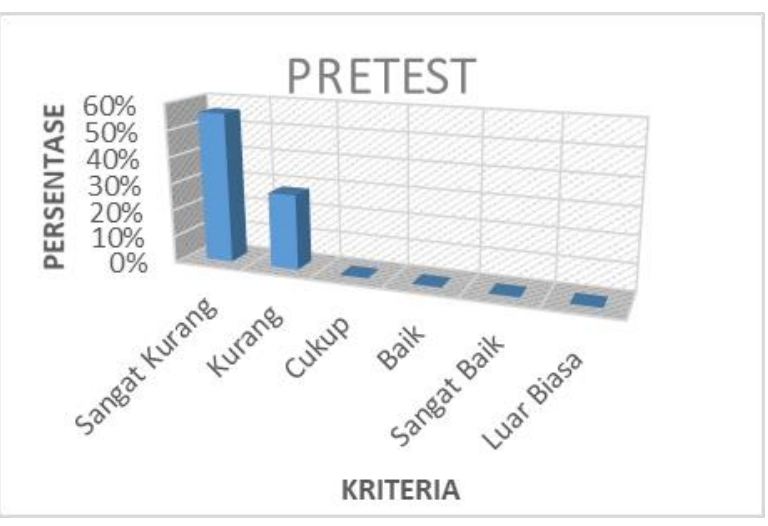

Gambar 1. Grafik Pretest 


\section{Deskripsi hasil data Posttest VO2max}

Hasil data dari Posttest diperoleh dengan nilai rata-rata 36,13 sebesar dan simpangan baku sebesar 2,16. Hasil Posttest ini disajikan dalam bentuk tabel frekuensi, diantaranya :

Tabel 3. Kriteria penilain Posttest

\begin{tabular}{llll}
\hline Kriteria & Nilai & Frekuensi & Persentase \\
\hline Sangat kurang & $<35,0$ & 8 & $32 \%$ \\
Kurang & $35,0-38,3$ & 12 & $48 \%$ \\
Cukup & $38,4-45,1$ & 5 & $20 \%$ \\
Baik & $45,2-50,9$ & 0 & $0 \%$ \\
Sangat baik & $51,0-55,9$ & 0 & $0 \%$ \\
Luar Biasa & $>55,9$ & 0 & $0 \%$ \\
\hline Jumlah & & 25 & $100 \%$ \\
\hline
\end{tabular}

Apabila ditampilkan pada diagram batang bisa dilihat pada tabel diawah ini:

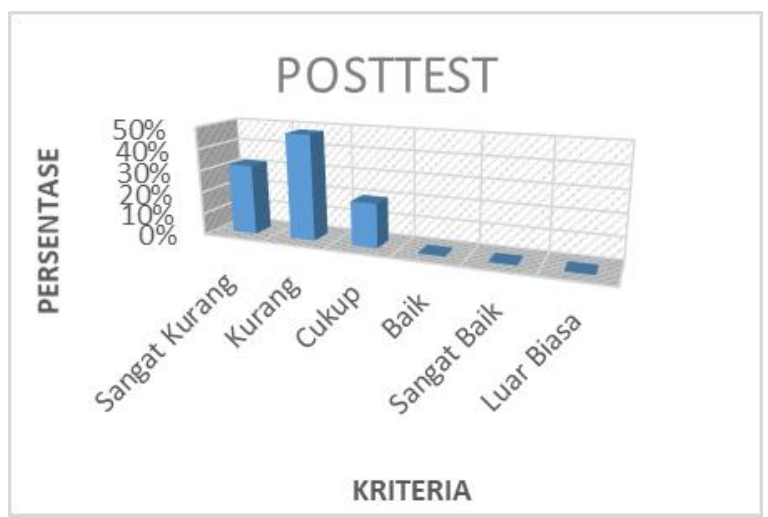

Gambar 2. Grafik Posttest

Uji Normalitas

Berdasarkan dari data yang telah terkumpul melalui proses penelitian yang dilaksanakan hingga data akhir, setelah adanya nilai rata - rata dan simpangan baku. Maka langkah yang selanjutnya akan dilakukan yaitu pengujian normalitas dengan menggunakan uji kolmogorov-smirnov. Bisa kita liat dalam tabel dibawah ini :

\section{Tabel 4. Hasil Perhitungan Uji Normalitas}

\begin{tabular}{llll}
\hline No & Variabel & Asymp.Sig & Kesimpulan \\
\hline 1 & Pretest & 0,200 & NORMAL \\
2 & Posttest & 0,200 & NORMAL \\
\hline
\end{tabular}

Nilai Signifikansi dari hasil Pretest sebesar 0,200 dan dari hasil Posttest sebesar 0,200. Karena nilai signifikasi dari kedua variabel lebih besar dari 0,05. Maka dapat dinyatakan hipotesis diterima dengan perkataan lain dapat dirumuskan bahwa distribusi "NORMAL".

Uji Homogenitas 
Dalam uji ini akan menguji hipotesis bahwa varians dari variabel- variabel tersebut sama, untuk menerima atau menolak hipotesis dengan membandingkan nilai signifikan lebih dari 0,05. Hasil uji homogenitas dapat dilihat pada tabel di bawah ini:

Tabel 5. Hasil Pengujian Uji Homogenitas

\begin{tabular}{llllllll}
\hline Test of Homogeneity of Variances & & & & \\
\hline hasil & & df1 & & df2 & & Sig. & \\
Levene Statistic & 1,547 & & 7 & & 11 & &, 248 \\
\hline
\end{tabular}

Dari perhitungan diperoleh signifikansi sebesar $0,248>0,05$. berarti varian sampel tersebut homogen, maka hipotesis yang menyatakan varians dari variabel diterima. Dengan demikian dapat ditarik kesimpulan bahwa varians populasi homogen. sehingga memenuhi persyaratan untuk melakukan uji-t.

Uji Hipotesis

Uji-t digunakan untuk menguji hipotesis ada tidaknya perbedaan yang signifikan berdasarkan hasil data Pretest dan Posttest. Apabila hasil tersebut menunjukan perbedaan yang signifikan maka Small Sided Games memberikan pengaruh terhadap peningkatan VO2max. Dasar pengambilan keputusan, jika nilai Sig.(2-tailed) $<0,05$, maka terdapat perbedaan yang signifikan dan jika nilai Sig.(2-tailed) > 0,05, maka tidak terdapat perbedaan yang signifikan.

Bisa kita lihat dalam tabel dibawah ini :

Tabel 6. Hasil Pengujian Uji-t

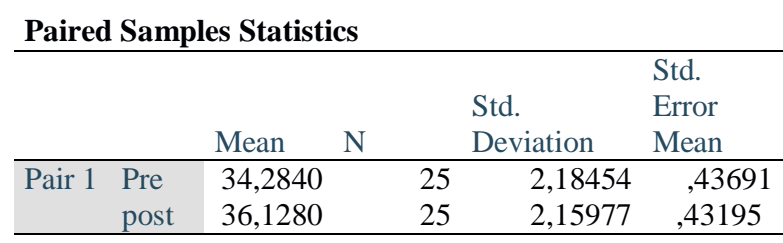

Hasil Uji-t diketahui bahwa nilai Sig.(2-tailed) $0,000<0,05$, maka hasil ini menunjukan terdapat perbedaan yang signifikan antara nilai Vo2max data Pretest dan Posttest. Artinya Small Sided Games memberikan pengaruh yang signifikan terhadap peningkatan VO2max.

Berdasarkan perhitungan data yang sudah dilakukan, menunjukan bahwa secara keseluruhan nilai VO2max para pemain sepakbola di PS Rick'Sayati sebelum melakukan treatment Small Sided Games, diantaranya : 14 orang yang mendapat kriteria sangat kurang, 11 orang yang mendapat kriteria kurang, dan setalah melakukan treatmen kriteria sangat kurang menjadi 8 orang, yang mendapat kriteria kurang menjadi 12, dan yang mendapat kriteria cukup ada 5 orang. Dilihat dari rerata sebelum melakukan treatment 
yaitu sebesar 34,28 dan setelah adanya treatment rerata menjadi 36,13. ternyata besarnya rerata setelah diberikan treatment meningkat sebesar 1,85. Adapun tabel persentase peningkatan dibawah ini :

Tabel 7. Persentase Peningkatan

\begin{tabular}{|l|l|l|}
\hline $\begin{array}{l}\text { Mean } \\
\text { Difference }\end{array}$ & $\begin{array}{l}\text { Mean } \\
\text { Pre-Test }\end{array}$ & Peningkatan \\
\hline 1,85 & 34,28 & $5,39 \%$ \\
\hline
\end{tabular}

Maka dapat dilihat diagram tersebut :

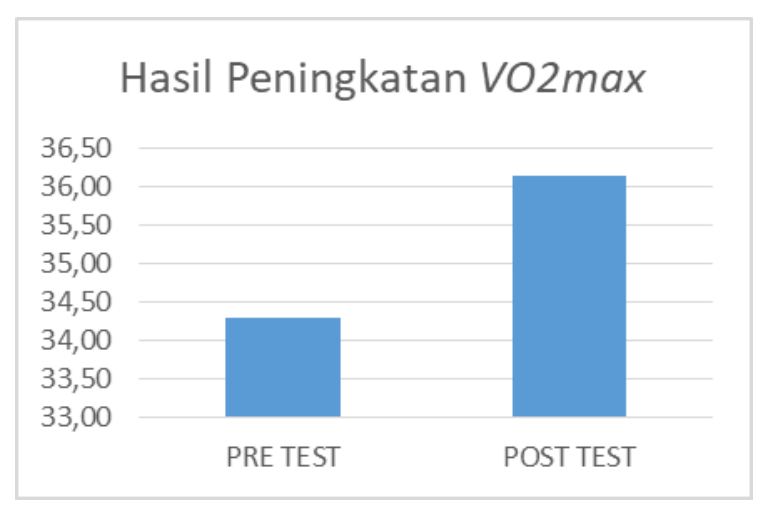

Gambar 3. Diagram Peningkatan

Hasil peningkatan tersebut dapat diperoleh karena pada metode Small Sided Games para pemain merasa senang dalam melakukannya, maka dari itu pemian akan lebih aktif bergerak dan agresif. Sehingga tidak terasa bahwa permainan tersebut sangat menguras tenaga. dalam permainan sepakbola kemampuan daya tahan aerobik yang baik atau VO2max yang tinggi sangat diprioritaskan.

Untuk memenuhi tuntutan daya tahan tersebut seorang harus mempunyai energi dalam jumlah banyak. Tuntutan energi dalam jumlah banyak itu akan diproduksi melalui sistem aerobik yang memerlukan oksigen, oleh karena itu tinggi rendahnya daya tahan seorang para pemain tergantung dari tinggi rendahnya kapasitas oksigen maksimal atau VO2max. Tinggi rendahnya VO2max para pemain sangat berpengaruh pada kondisi fisik atau kesegaran jasmani pemain.

Hasil dari penelitian yang telah dianalisis dengan menggunakan teknik analisis paired sample T-test dengan taraf signifikansi 0,05 (5\%). Dari uji tersebut diperoleh nilai sig $0,000<0,05$. Sehingga dapat disimpulkan bahwa terdapat pengaruh yang signifikan metode Small Side Games terhadap peningkatan VO2max pada pemain sepak bola di PS 
Rick's Sayati. Apabila dilihat dari data mean difference sebesar 1,85. Maka Peningkatan persentase tersebut sebesar 5,39\%.

\section{Pembahasan}

Data hasil penelitian yang telah di deskripsikan diatas, menunjukan bahwa terdapat pengaruh yang signifikan dari penerapan metode Samll Sided Games terhadap peningkatan VO2max pada pemain sepak bola PS Rick's Sayati.

Small Sided Games dapat dibentuk dengan berbagai macam modifikasi. Dengan menerapkan aturan-aturan untuk mencapai tujuan tertentu, Small Sided Games memiliki berbagai macam bentuk. Permainan tiga lawan tiga, empat lawan empat adalah contoh dari Small Sided Games. Small Sided Games adalah bentuk latihan dengan area yang lebih kecil dari area yang digunakan untuk permainan sebenarnya. Jumlah pemainnya pun juga lebih sedikit dengan harapan jumlah sentuhan bola pada pemain lebih banyak (Studi \& Jasmani, n.d.).

Small Sided Games merupakan salah satu permainan yang mengacu pada permainan sepakbola tetapi permainan ini ada batasannya. Seperti pemain, lapangan dan waktunya serta memakai aturan yang sudah di modifikasi. Permainan Small Sided Games dengan ukuran lapang yang yang lebih kecil dan jumlah pemain sedikit memungkinkan pemain sering terlibat dalam permainan. Pemain akan aktif bergerak dalam upaya merebut dan mempertahankan bola dengan tempo yang tinggi. Permainan ini sangat baik untuk meningkatkan daya tahan atau memperbaiki nilai VO2max pemain. Para pemain dalam Small Sided Games dituntut harus bergerak cepat, terutama ketika mengambil keputusan dalam permainan harus berfikir cepat. Karena kondisi lapangan yang sangat dibatasi, maka dari itu permainan Small Sided Games sangat berpengaruh terhadap peningkatan VO2max.

Pembentukan VO2max dapat dipengaruhi oleh 4 faktor, yaitu: umur, jenis kelamin, latihan, dan tinggi daratan.

1. Umur : Faktor utama yang mempengaruhi akan besarnya kandungan oksigen seseorang. Secara umum VO2max pada usia 20 tahun merupakan angka volume oksigen tertinggi pada usia manusia, serta akan mengalami penurunan hingga $30 \%$ pada usia 65. Semakin bertambahnya usia, maka semakin berkurang pula kinerja organ tubuh manusia. Akan tetapi, orang yang tetap aktif menjalani rutinitas berolahraga disaat usia lanjutnya akan mengalami penurunan VO2max sedikit demi sedikit, penurunan ini tidak sedrastis dengan orang tua yang sudah tidak berolahraga sama sekali. 
2. Gender (jenis kelamin) : Umumnya laki-laki memiliki tingkat level VO2Max lebih tinggi 40-60\% dibandingkan wanita. Sedangkan wanita memiliki kemampuan aerobic $20 \%$ lebih rendah dari pria yang sama usianya. Perbedaan hormon inilah yang menyebabkan produksi hemoglobin wanita lebih rendah dan kadar lemak pada tubuh lebih besar. Disamping itu wanita memiliki otot lebih kecil dari pria.

3. Latihan : hal terpenting dalam pembentukan VO2Max adalah pola latihan yang tersusun dan direncanakan. Seringnya berolahraga dapat membuat paru-paru menjadi besar bila ditinjau dari segi fisiologis, itu artinya intensitas oksigen yang dihirup akan lebih banyak masuk kedalam sel-sel otot yang bekerja sehingga semakin kuatlah ketahanan fisik orang tersebut. Berlatih secara teratur serta dilakukan berulang-ulang, diyakini dapat mengubah tinggi rendahnya VO2Max pada seseorang. Seringnya berlatih aerobic dapat membantu seseorang untuk memiliki kandungan VO2Max lebih besar, meskipun ia memiliki kadar oksigen setara orang lain pada umumnya.

4. Tinggi dataran : Dengan komposisi udara yang menipis di dataran tinggi, akan lebih merespon kardiovaskuler untuk lebih aktif merangsang pembentukan VO2Max lebih tinggi lagi.

Sampel yang digunakan dalam penelitian ini ialah tim PS Rick's sayati. Dalam tim tersebut setelah dilakukan observasi di lapangan dan menganalisis kekurangan tim ialah daya tahan atau nilai VO2max yang dimiliki pemain masih rendah, program latihan yang diberikan pelatih untuk meningkatkan VO2max, memakai interval training dan circuit training. Program latihan tersebut membuat pemain sudah terbiasa dengan cara itu, maka dari itu pemain merasa males dan jenuh untuk melakukan latihan tersebut, karena pemain merasa terpaksa, jadi tidak ada kemauan dari diri sendiri. Menurut beberapa pelatih berpendapat bahwa ketika pemain tidak ada kemauan dari dalam diri maka tidak akan mendapatkan hasil yang baik, meskipun terus dipaksa. Sebagai dorongan internal dan eksternal dalam diri seseorang yang diindikasikan dengan adanya hasrat dan minat, dorongan dan kebutuhan, harapan dan cita-cita, penghargaan dan penghormatan(Kjøsnes, 2014).

Perlakukan dalam penelitian ini diberikan 18 kali pertemuan, dengan rincian latihan tiap minggu sebanyak 3 kali perminggu. Rincian perlakuannya ada di table 8 berikut ini: 
Tabel 8. Rincian perlakuan

\begin{tabular}{|c|c|}
\hline $\begin{array}{l}\text { Pertemuan } \\
\text { ke- }\end{array}$ & Rincian program \\
\hline 1 & Pre-Test dan pengukuran VO2max menggunakan Bleep Test. \\
\hline $2-3$ & $\begin{array}{l}\text { latihan small sided games menggunakan } 4 \text { vs } 4 \text { dengan ukuran lapangan } 30 \\
\text { x } 20 \text { meter perkelompok }\end{array}$ \\
\hline $4-5$ & $\begin{array}{l}\text { latihan small sided games } 4 \text { vs } 4 \text { dengan ukuran lapangan } 30 \text { x } 20 \text { meter } \\
\text { memakai } 4 \text { gawang kecil }\end{array}$ \\
\hline 6 & $3+3$ vs 3 dengan ukuran lapangan $30 \times 20$ meter \\
\hline 7 & $\begin{array}{l}\text { latihan small sided games dengan ukuran lapangan } 30 \text { × } 25 \text { meter dengan } \\
\text { waktu } 3 \text { x } 4 \text { menit }\end{array}$ \\
\hline $8-9$ & latihan small sided games dengan ukuran lapangan 25 x 10 meter \\
\hline $10-11$ & latihan small sided games 5 vs 2 dengan ukuran lapangan 20 x 40 meter \\
\hline 12 & latihan small sided games 5 vs 3 dengan ukuran lapangan $30 \times 15$ meter \\
\hline 13 & latihan small sided games 8 vs 4 dengan ukuranl apangan $20 \times 20$ meter \\
\hline 14 & $\begin{array}{l}\text { latihan small sided games 3vs1 - 5vs3 dengan ukuran lapangan } 20 \text { x } 20 \\
\text { meter }\end{array}$ \\
\hline 15 & $\begin{array}{l}\text { latihan small sided games } 2 \mathrm{vs} 1-5 \mathrm{vs} 2 \text { dengan ukuran lapangan } 20 \text { x } 20 \\
\text { meter }\end{array}$ \\
\hline $16-17$ & $\begin{array}{l}\text { latihan small sided games } 5 \text { vs } 5,1 \text { kiper dan } 4 \text { pemain dengan ukuran } \\
\text { lapangan } 35 \text { x } 25 \text { meter }\end{array}$ \\
\hline 18 & $\begin{array}{l}\text { Post Test VO2max dengan menggunakan Bleep Test }(\mathrm{F} . \text { M. Clemente et al., } \\
\text { 2014) }\end{array}$ \\
\hline
\end{tabular}

Setelah menempuh proses penelitian dengan memberikan treatment atau perlakuan selama 18 kali pertemuan termasuk pretest dan posttest dengan kurung waktu selama 6 minggu, hasil pengolahan data diperoleh data mean difference sebesar 1,85 dari hasil pretest-posttest. Maka Peningkatan persentase tersebut sebesar 5,39\%. Sehingga dapat disimpulkan bahwa terdapat pengaruh yang signifikan metode Small Side Games terhadap peningkatan VO2max pada pemain sepak bola di PS Rick's Sayati.

Penelitian memberikan gambaran baru bahwa dengan menerapkan latihan small sided games dapat meningkatkan VO2max pemain sepak bola. Hasil penelitian ini juga mendukung hasil penelitian terdahulu bahwa terdapat peningkatan terhadap kemampuan kapasitas anaerobik lebih signifikan melalui pola Small Sided Games metode interval dibandingkan dengan pola Small Sided Games metode repetisi(Pramdhan, n.d.). Permainan Small Sided Games memungkinkan pelatih untuk fokus pada aspek teknis/taktis pada pemain sepak bola(Sannicandro et al., 2016). Hasil uji lanjut dengan LSD diketahui bahwa kelompok eksperimen I dengan bentuk pelatihan Small Sided Games Three-A-Sided lebih efektif dalam meningkatkan Cardiovascular Endurance(Studi \& Jasmani, n.d.). Kapasitas aerobic dalam sepak bola professional pria memberikan efek besar pada tingkat kerja $\operatorname{VO2max}$ (Tønnessen et al., 2013). 


\section{KESIMPULAN}

Berdasarkan hasil pembahasan yang telah dilakukan, maka dapat ditarik kesimpulan bahwa adanya pengaruh Small Sided Games terhadap peningkatan VO2max pada pemain sepak bola di PS Rick's Sayati.

\section{DAFTAR PUSTAKA}

Alex, kertamanah. (2015). Teknik Dan Taktik Permainan Tenis Meja. Bandung: Remaja Rosdakarya.

Barnett, L. M., Hardy, L. L., Lubans, D. R., Cliff, D. P., Okely, A. D., Hills, A. P., et al. (2013). Australian children lack the basic movement skills to be active and healthy. Movement Skills to Be Active and Healthy. Health Promotion Journal of Australia: Official Journal of Australian Association of Health Promotion Professionals, 2, 24, 82-84.

Chu, C. Y., Chen, I. T., Chen, L. C., Huang, C. J., \& Hung, T. M. (2012). Sources of psychological states related to peak performance in elite table tennis players. International Journal of Table Tennis Sciences, 7, 86 -90.

Evelen. (2010). Teori Belajar Dan Pembelajaran. bogor: Ghalia Indonesia.

Husdarta. (2011). Belajar dan Pembelajaran. Bandung: Dewa Ruchi.

James, T. (2016). Macam - Macam Metodologi Penelitian. Jakarta: Lensa Media Pustaka.

Mu'rifah. (2002). Pengaruh Gaya mengajar dan motor educability terhadap hasil belajar servis tangan atas permainan bola voli": suatu studi eksperimen di SMU Negeri 103 Jakarta 2001. Jakarta: Tesis : Program Pascasarjana UNJ Jakarta.

Muska Moston and Sara Asworth. (2008). Teacing Physical Education. New York: Macmillan College Publising Company Inc.

Peter, S. (2008). teknik bermain pingpong. Bandung: Pinior jaya.

Pradas, F., Rapún, M., Martínez, P., Castellar, C., Bataller, V., \& Carrasco, L. (2011). An analysis of jumping force manifestation profile in table tennis. 3-7.

Rea, pica. (2010). Motor skill matter. young children on the. Beyound the Journal.

S.Nasution. (2010). Dedaktik Asas-Asas Mengajar. Jakarta: Bumi Aksara.

Sayiful Bachri. (2010). Strategi belajar mengajar. Banjarmasin: Rineka cipta.

Sukma, A. (2016). Buku olahraga paling lengkap. Jakarta: Serambi Semesta.

Sukoco. (2012). Model pengembangan keterampilan motorik. Jakarta: Depdikbut.

Syarif Sumantri, M. (2015). Strategi Pembelajaran. Jakarta: Raja grafindo Persada.

Tomoliyus. (2012). Panduan Kepelatihan Tenis Meja Bagi Siswa Sekolah Dasar. Yogyakarta: Fakultas Ilmu Keolahragaan. Universitas Negeri Yogyakarta.

Trimo, S. (2009). Perbandingan Model Pembelajaran Kontekstual (Contextual Teaching 
and Learning) dan Umpan Balik Berpasangan (Resiprokal) Terhadap Hasil Belajar Lari Cepat ditinjau dari Kemampuan Motor Ability pada SMPN 23 Kota Tangerang. Jakarta: Tesis : Program Pascasarjana UNJ Jakarta.

Widiastuti. (2015). Tes Dan Pengukuran Olahraga. Jakarta: Rajawali press.

Zaelan. (2013). Pengembangan model pembelajaran resipokal teaching untuk meningkatkan aktifitas dan prestasi belajar siswa. Bandung: Hursada.

Zagatto, A. M., Milioni, F., \& Freitas, I. F. (2015). Body composition of table tennis players : comparison between performance level and gender Body composition of table tennis players: comparison between performance level and gender. (November). https://doi.org/10.1007/s11332-015-0252-y 